\title{
Propofol or sevoflurane anesthesia without muscle relaxants allow the early extubation of myasthenic patients
}

\author{
[L'anesthésie au propofol ou au sévoflurane, sans myorelaxants, permet une extu- \\ bation précoce chez des patients myasthéniques]
}

Giorgio Della Rocca MD, ${ }^{*}$ Cecilia Coccia MD, ${ }^{*}$ Laura Diana MD, $\dagger$ Livia Pompei MD, ${ }^{*}$ Maria G. Costa MD, ${ }^{*}$ Eleonora Tomaselli MD,$\dagger$ Pierangelo Di Marco MD,$\dagger$ Vincenzo Vilardi MD, ${ }^{*}$ Paolo Pietropaoli MD $\dagger$

\begin{abstract}
Purpose: To compare two non-muscle relaxant anesthetic techniques in myasthenic patients undergoing trans-sternal thymectomy, evaluating the intra- and postoperative conditions including the early extubation in the operating room.
\end{abstract}

Methods: Sixty-eight consecutive myasthenic patients undergoing trans-sternal thymectomy were prospectively randomized in two groups: propofol and sevoflurane. In both groups anesthesia was induced with propofol ( $\left.1-2 \mathrm{mg} \cdot \mathrm{kg}^{-1}\right)$ and intubation performed after topical anesthesia of the airway with lidocaine. Anesthesia was maintained in the propofol group (36 patients) with a continuous propofol infusion (3-6 mg. $\mathrm{kg}^{-1} \cdot \mathrm{hr}^{-1}$ ) and nitrous oxide and, in the sevoflurane group (32 patients), with sevoflurane (end-tidal $\mathrm{I}-1.5 \%$ ) in $\mathrm{O}_{2}: \mathrm{N}_{2} \mathrm{O}$. Intubating conditions, hemodynamic changes, neuromuscular transmission, postoperative intensive care unit and hospital length of stay and complications were evaluated. Data were analyzed with repeated measure two-way analysis of variance (ANOVA), Chi square test and Student's t test.

Results: Intubating conditions were good in all patients. There were no hemodynamic changes. All patients were extubated in the operating room and none had to be re-intubated for postoperative respiratory depression. Neuromuscular transmission showed minimal changes, more important in the sevoflurane group, and at the end of the procedure the recovery was complete in all patients. We did not observe any other significant differences between the two groups studied.

Conclusion: Our data show that these two anesthetic techniques allow the early extubation of myasthenic patients in the operating room.
Objectif : Comparer deux techniques anesthésiques sans myorelaxants chez des patients myasthéniques, devant subir une thymectomie trans-sternale, en évaluant les conditions peropératoires et postopératoires, y compris l'extubation précoce dans la salle d'opération.

Méthode : Soixante-huit patients myasthéniques consécutifs, admis pour une thymectomie, ont été répartis de façon aléatoire en deux groupes : propofol et sévoflurane. L'anesthésie a été induite, chez tous les patients, avec du propofol $\left(1-2 \mathrm{mg} \cdot \mathrm{kg}^{-}\right)$et l'intubation réalisée à la suite de l'anesthésie topique des voies aériennes avec de la lidocaiine. Dans le groupe propofol, de 36 patients, l'anesthésie a été maintenue avec une perfusion continue de propofol (3-6 mg. $\left.\mathrm{kg}^{-1} \cdot \mathrm{hr}^{-1}\right)$ et du protoxyde d'azote et, dans le groupe sévoflurane, de 32 patients, avec du sévoflurane ( $1-1,5 \%$ télé-expiratoire) dans un mélange $\mathrm{O}_{2}: \mathrm{N}_{2} \mathrm{O}$. Les conditions d'intubation, les modifications hémodynamiques, la transmission neuromusculaire, la durée du séjour aux soins intensifs et à l'hôpital ainsi que les complications ont été évaluées. Nous avons utilisé une analyse de variance bilatérale de mesures répétées (ANOVA), le test du chi carré et le test $t$ de Student.

Résultats : Les conditions d'intubation ont été bonnes pour tous les patients. II n'y a pas eu de modifications hémodynamiques. Tous les patients ont été extubés dans la salle d'opération et aucun n'a dû subir une nouvelle intubation pour dépression respiratoire postopératoire. La transmission neuromusculaire a affiché des changements minimaux, plus importants dans le groupe sévoflurane et, à la fin de l'opération, la récupération était complète chez tous les patients. Nous n'avons pas observé d'autres différences intergroupes significatives.

Conclusion : Nos données montrent que les deux techniques anesthésiques permettent une extubation précoce, dans la salle d'opération, chez des patients myasthéniques.

From the Departments of Anesthesia, University of Udine, ${ }^{*}$ Udine; and the University of Rome "La Sapienza", $†$ Rome, Italy. Address correspondence to: Prof. Giorgio Della Rocca, Corso Trieste 169/a, 00198 Rome, Italy. Phone: +39 0432 559500-1;

Fax: +39 0432 559512/545526; E-mail: giorgio.dellarocca@dsc.uniud.it Accepted for publication August 21, 2002.

Revision accepted March 3, 2003. 
M YASTHENIA gravis (MG) is an acquired autoimmune disorder characterized by a reduction of postsynaptic nicotinic acetylcholine receptors at the neuromuscular junction, mainly caused by their destruction or inactivation by circulating antibodies $(\operatorname{IgG}){ }^{1}$ Muscular weakness and easy fatigability are the hallmarks of this disease and the balance between active and lost receptors determines clinical symptoms. The role of the thymus in MG has been suggested by the evidence that $10-15 \%$ of patients present a thymoma and at least $60 \%$ thymus hyperplasia or dysplasia and by the beneficial effects of thymectomy in 40 to $90 \%$ of patients. ${ }^{2}$ The myasthenic patient represents a significant challenge for the anesthesiologist; in fact these patients are known to be unusually sensitive to non-depolarizing muscle relaxants agents, commonly used during anesthesia, ${ }^{3}$ and for the risk of postoperative respiratory failure that may result from stress induced exacerbation of $\mathrm{MG}$ (myasthenic crisis) or other adverse drug interactions (antibiotics or antiarrhythmics).

In this study we compared two non-muscle relaxant anesthetic techniques, the first with propofol and the second with sevoflurane, in myasthenic patients undergoing trans-sternal thymectomy. The first objective was to evaluate the feasibility to extubate patients in the operating room and the second was to document perioperative complications.

\section{Methods}

Sixty-eight consecutive myasthenic patients undergoing trans-sternal thymectomy were a priori randomly assigned to one of the treatment groups (GraphPad StateMate 1.0, 1995. San Diego, CA, USA).

\section{Monitoring}

Intraoperative monitoring included electrocardiogram, arterial blood pressure monitoring (PCM SpaceLabs Inc.Redmond, WA, USA), pulse oximetry, end-tidal $\mathrm{CO}_{2}\left(\mathrm{EtCO}_{2}\right)$ and expiratory gas analysis (Cato Drager Werk HG Lubeck, Germany). Neuromuscular transmission was monitored with TOF-Guard (Organon Teknika Turnhout, Belgium). The forearm was immobilized in order to prevent interfering movements. The ulnar nerve was stimulated supramaximally at the wrist with train-offour stimuli ( $60 \mathrm{~mA}$ for $200 \mu \mathrm{sec}$ ) at 15 -sec intervals and the acceleration of the thumb was measured. Baseline twitch amplitude was established after induction of anesthesia. Tl was recorded as percentage of baseline measure and TR was recorded as ratio between the fourth and the first twitch $(\mathrm{T} 4 / \mathrm{Tl})$. Skin temperature was monitored and maintained above $32^{\circ} \mathrm{C}$.

\section{Anesthetic technique}

No patient was premedicated. Before induction of anesthesia lidocaine $2 \%$ and $10 \%$ spray were used for topical anesthesia of the pharynx and larynx. After three to five minutes of preoxygenation with $100 \%$ oxygen by facemask, anesthesia was induced with fentanyl $\left(2-5 \mu \mathrm{g} \cdot \mathrm{kg}^{-1}\right)$, droperidol $\left(0.07-0.1 \mathrm{mg} \cdot \mathrm{kg}^{-1}\right)$ and propofol $\left(1-2 \mathrm{mg} \cdot \mathrm{kg}^{-1}\right)$. During laryngoscopy topical anesthesia of the vocal cords and trachea was obtained with the application of lidocaine 2\% (LTA Kit, Abbott, Sligo, Ireland). After two minutes the trachea was intubated with a single-lumen tube. All patients received lactated Ringer's solution (7-8 $\mathrm{mL} \cdot \mathrm{kg}^{-1} \cdot \mathrm{hr}^{-1}$ ) during the procedure.

Mechanical ventilation was adjusted to maintain the $\mathrm{EtCO}_{2}$ between $30-35 \mathrm{mmHg}$ with a respiratory rate of 14 breath $\cdot \mathrm{min}^{-1}$, a tidal volume of $8 \mathrm{~mL} \cdot \mathrm{kg}^{-1}$ and an inspiration-expiration ratio of $1: 2$.

In the propofol group anesthesia was maintained with nitrous oxide and oxygen (70:30) and a continuous infusion of propofol $\left(3-6 \mathrm{mg} \cdot \mathrm{kg}^{-1} \cdot \mathrm{hr}^{-1}\right)$ and supplemented by fentanyl boluses $\left(0.7 \mu \mathrm{g} \cdot \mathrm{kg}^{-1}\right)$ as required.

In the sevoflurane group anesthesia was maintained with sevoflurane (end-tidal $1-1.5 \%)$, nitrous oxide and oxygen (70:30) and fentanyl $\left(0.7 \mu \mathrm{g} \cdot \mathrm{kg}^{-1}\right)$ as required.

A continuous sufentanil iv infusion $(0.002$ $\left.\mu \mathrm{g} \cdot \mathrm{kg}^{-1} \cdot \mathrm{min}^{-1}\right)$ was given for postoperative pain relief in both groups trough an elastomeric device (2C1075 Baxter Healthcare Corporation; Deerfield, IL, USA). The continuous infusion was started before skin incision.

The evaluation of intraoperative conditions included intubating condition (jaw relaxation, laryngoscopy and vocal cord abduction) as reported by VibyMogensen. ${ }^{4}$ Hemodynamic changes [mean arterial pressure $(\mathrm{mAP})$ and heart rate $(\mathrm{HR})]$ and intraoperative neuromuscular transmission ( $\mathrm{Tl}$ and $\mathrm{TR}$ ) were recorded at times $0=$ baseline, $30,60,120 \mathrm{~min}$ and final $=$ at the end of anesthesia. At the end of surgery time from the end of anesthesia to extubation $(\Delta t$ extubation), time from the end of anesthesia to eye opening and recovery of consciousness ( $\Delta \mathrm{t}$ awake) were recorded. All major complications (respiratory depression, respiratory failure and cardiovascular events) or other minor postoperative complications were recorded in both groups.

At the end of surgery all patients were extubated in the operating room and transferred to the intensive care unit (ICU).

\section{Statistical analysis}

Patient age and body surface area (BSA), preoperative pyridostigmine dosage $\left(\mathrm{mg} \cdot \mathrm{day}^{-1}\right)$, intraoperative sevoflurane and propofol administration, mAP and 
TABLE I Demographic and preoperative characteristics of patients in the sevoflurane and propofol groups

\begin{tabular}{|c|c|c|}
\hline & $\begin{array}{l}\text { Propofol } \\
(n=36)\end{array}$ & $\begin{array}{l}\text { Sevoflurane } \\
(n=32)\end{array}$ \\
\hline Gender: $\mathrm{M} / \mathrm{F}$ & $14 / 22$ & $12 / 20$ \\
\hline $\begin{array}{l}\text { Age (SD) } \\
(\mathrm{yr})\end{array}$ & $40(14)$ & $44(18)$ \\
\hline $\begin{array}{l}\text { Body surface area }(\mathrm{SD}) \\
\left(\mathrm{m}^{2}\right) \\
\text { Osserman's staging }\end{array}$ & $1.83(0.35)$ & $1.78(0.25)$ \\
\hline I & 6 & 4 \\
\hline $\mathrm{IIa} / \mathrm{IIb}$ & $10 / 15$ & $12 / 14$ \\
\hline III & 5 & 2 \\
\hline \multicolumn{3}{|l|}{ Preoperative treatment } \\
\hline -Pyridostigmine (\#pts) & 36 & 32 \\
\hline$-\mathrm{mg} \cdot \mathrm{day}^{-1}(\mathrm{SD})$ & $240(60)$ & $240(60)$ \\
\hline -Prednisone (\#pts) & 21 & 16 \\
\hline -Plasmapheresis (\#pts) & 7 & 4 \\
\hline $\mathrm{Fev} 1$ ( $\%$ of predicted value) & 80 & 82 \\
\hline [range] & {$[68-90]$} & {$[71-93]$} \\
\hline
\end{tabular}

Data are expressed as mean (SD) or as mean (range). Fevl $=$ forced expiratory volume in the first second; \#pts = number of patients.
HR, intraoperative neuromuscular transmission and postoperative blood gas data are recorded as mean (SD). Preoperative Fevl, duration of surgery and anesthesia, $\Delta \mathrm{t}$ extubation, $\Delta \mathrm{t}$ awake, ICU and hospital postoperative length of stay are expressed as mean and range. Differences between groups in preoperative Osserman classes and preoperative treatment are analyzed with Chi square test. Differences in demographic patient characteristics (age and BSA), preoperative treatment with pyridostigmine, preoperative Fevl, duration of surgery and anesthesia, $\Delta t$ extubation and $\Delta \mathrm{t}$ awake were analyzed with Student's $\mathrm{t}$ test. Neuromuscular transmission variables and intraoperative $\mathrm{mAP}$ and $\mathrm{HR}$, at different times within groups and between groups were analyzed with repeated measure two-way analysis of variance (ANOVA). All statistical analyses were computed by SPSS for Windows (version 8.0, 1997, SPSS Inc, Chicago, IL, USA). Statistical differences were considered significant when $P<0.05$.

\section{Results}

Demographic and preoperative patient characteristics are presented in Table I. Intubating conditions were excellent in 35 of the 36 propofol group patients and in 30 of the 32 sevoflurane group patients.

TABLE II Duration of surgery and anesthesia, time to extubation and to awakening, postoperative blood gas values, postoperative complications

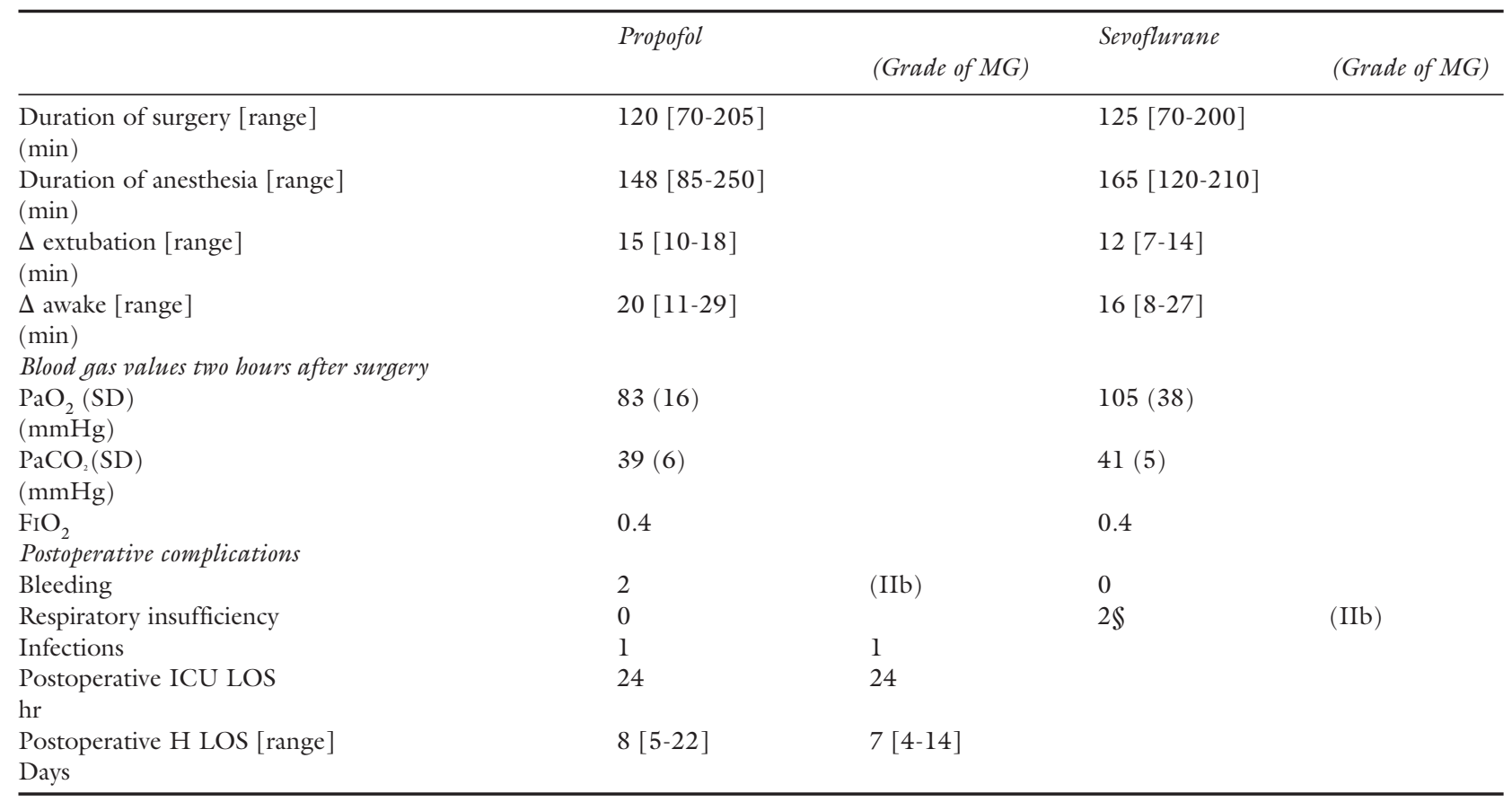

Data are expressed as mean [range] or as mean $(\mathrm{SD})$; grade of myasthenia gravis $(\mathrm{MG})=$ Osserman's staging; ICU = intensive care unit; LOS = length of stay; $\mathrm{H}=$ hospital; $\mathbb{S}=$ one obese and one 70 -yr-old. 


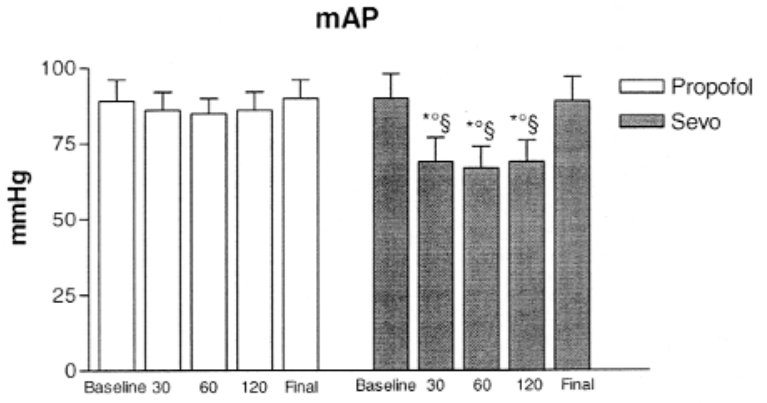

HR

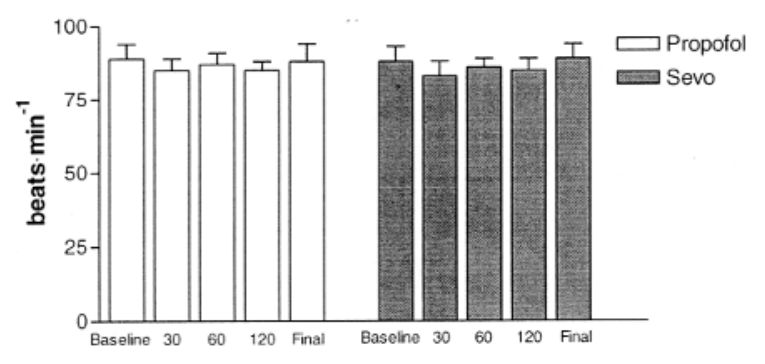

FIGURE 1 Mean arterial pressure (MAP) and heart rate (HR) in the propofol and sevoflurane groups at zero (baseline), 30, 60, and $120 \mathrm{~min}$ (during surgery) and at the end of surgery (final). ${ }^{*} P$ $<0.05$ compared to baseline; ${ }^{\circ} \mathrm{P}<0.05$ compared to final; $\$ P<$ 0.05 compared to the same moment in the propofol group.

Duration of anesthesia and surgery, time to extubation and to awakening, and postoperative complications are presented in Table II and were similar in both groups. No hemodynamic response to skin incision or sternotomy occurred and no patient movement in response to surgery was observed in both groups.

In the propofol group the mean continuous infusion of propofol was $4.8^{1} \mathrm{mg} \cdot \mathrm{kg}^{-1} \cdot \mathrm{hr}^{-1}$, equal to 758 (60) $\mathrm{mg}$ of propofol per patient, with a mean number of fentanyl boluses of $2 .{ }^{1}$ During anesthesia HR did not change, while mAP decreased $25 \%$ compared to the baseline during surgery and returned to preoperative values at the end of anesthesia (Figure 1). Neuromuscular transmission remained stable during the procedure (Figure 2).

In the sevoflurane group the mean end-tidal sevoflurane was $1.4(0.3) \%$ and the mean number of fentanyl boluses given during the surgical procedure was $2 .{ }^{1}$ During anesthesia we did not observe changes in HR and mAP. (Figure 1). Single twitch and train-
Propofol Group
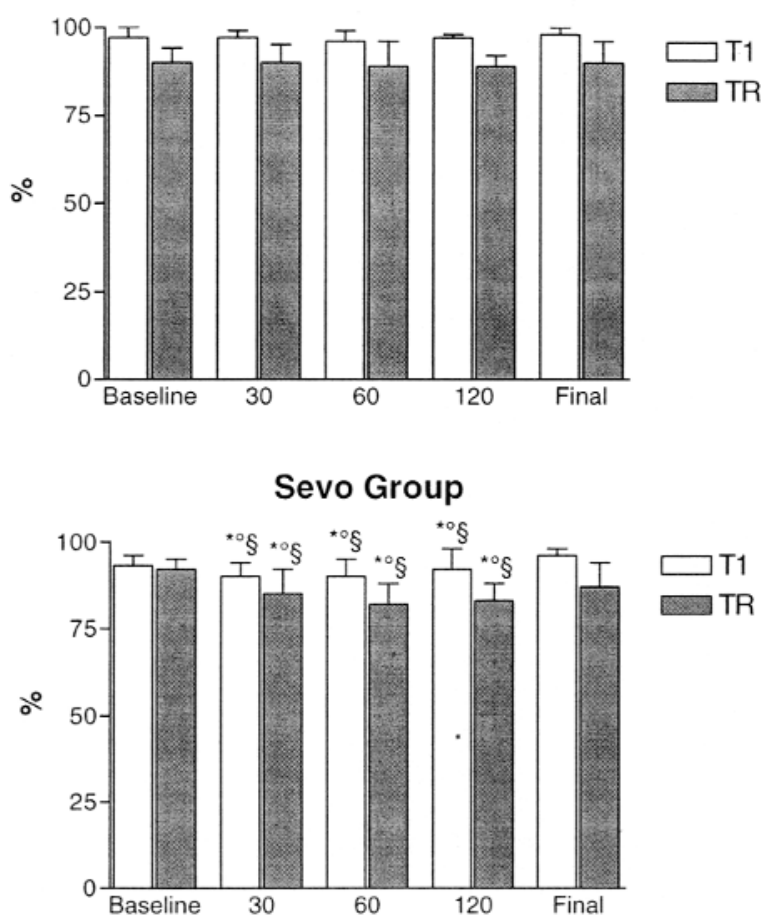

FIGURE 2 Neuromuscular transmission in the propofol and sevoflurane groups at zero (baseline), 30, 60, and $120 \mathrm{~min}$ (during surgery) and at the end of surgery (final). $\mathrm{Tl}=$ first twitch $(\%) ; \mathrm{TR}=\mathrm{T} 4 / \mathrm{T} 1$ ratio. ${ }^{*} P<0.05$ compared to baseline; ${ }^{\circ} \mathrm{P}<$ 0.05 compared to final; $\$ P<0.05$ compared to the same moment in the propofol group.

of-four decreased 10 to $15 \%$ compared to baseline at 30,60 and $120 \mathrm{~min}(P<0.05)$ and recovered completely after anesthesia (Figure 2). Tl and TR decreased 5 to $8 \%$ at 30,60 and $120 \mathrm{~min}(P<0.05)$ compared to the propofol group and recovered completely at the end of anesthesia.

Arterial blood gases two hours after surgery were normal in both groups (Table II). Two patients of the propofol group were reoperated for bleeding after surgery and were ventilated mechanically for 12 and $24 \mathrm{hr}$. Two patients of the sevoflurane group (Osserman Class IIb; one 70-yr-old and the other obese) were transferred back to the ICU for hypoxemia. They did not require tracheal intubation and were discharged 48 and 96 hr later respectively.

\section{Discussion}

The main findings of the present study are that anesthesia with either sevoflurane or propofol and nitrous oxide plus opioids, but without muscle relaxants, 
allow early extubation in the operating room in myasthenic patients undergoing trans-sternal thymectomy.

The intubating conditions were good in all patients. There were only minimal hemodynamic changes in the propofol group. All patients were extubated in the operating room and in no case they had to be intubated for postoperative respiratory depression. Neuromuscular transmission showed minimal changes, more important in the sevoflurane group, and at the end of the procedure the recovery was complete in all patients. We did not observe any other significant differences between the two groups studied.

Our data show that these two anesthetic techniques allow the early extubation of myasthenic patients in the operating room. No postoperative anesthesiarelated complications were recorded.

Several anesthetic techniques have been described for the management of myasthenic patients. The use of muscle-relaxants in patients with $\mathrm{MG}$ has been associated with a higher rate of unsuccessful extubation at the end of surgery and with longer postoperative mechanical ventilation and hospital stay. ${ }^{2,5} \mathrm{We}$ avoided muscle relaxants in myasthenic patients because the neuromuscular effects of non-depolarizing muscle relaxants are known to be prolonged in patients with MG. ${ }^{1}$ The speed of onset of neuromuscular block is accelerated, the degree of block is potentiated and the rate of recovery is decreased. ${ }^{6}$ Chevalley et al. described the evolution of the perioperative management of myasthenic patients undergoing thymectomy and the possibility to predict the need for systematic postoperative ventilation. ${ }^{2}$ They observed that postoperative ventilatory support was more frequently required when a balanced technique was used, particularly in patients who received muscle relaxants. Our findings support the results of that article as we did not use any muscle relaxants and we extubated all patients early in the operating room.

We compared two anesthetic techniques in a large number of myasthenic patients. The use of propofol in MG has been described in the literature in small study groups or case reports. ${ }^{7,8}$ When propofol was used for induction and maintenance of anesthesia, patients were extubated in the operating room and did not require postoperative respiratory support. ${ }^{9}$ This drug has been shown to obtund airway reflexes and allow a relatively easy intubation in the majority of patients. ${ }^{10}$ Similar results with the same induction technique as used in this study have been reported previously in non-myasthenic patients. ${ }^{10,11}$

MG patients are also more sensitive than normal to neuromuscular depression by volatile anesthetic agents such as halothane and isoflurane. ${ }^{12-14}$ In our series, neuromuscular trasmission during surgery was more depressed with the use of sevoflurane compared with propofol, but it recovered completely at the end of anesthesia so that the mean $\Delta$ extubation and mean $\Delta$ awake were similar in both groups.

The rapid elimination of propofol ${ }^{15}$ and the rapid kinetic (low blood gas solubility coefficient) of sevoflurane allowed fast recovery of consciousness, airway reflexes and respiratory function at the end of surgery, precluding a prolonged period of intubation and mechanical ventilation. ${ }^{16,17}$ Only two patients (a 70 -yr-old and an obese patient) in the sevoflurane group were transferred back in the ICU for postoperative hypoxemia but mechanical respiratory support was not necessary.

Thymectomy is performed in patients with initial symptoms of the disease so the majority of patients in this study were in Osserman's class I or II, with no preoperative respiratory depression. It is a subject of debate if the determinants of postoperative mechanical ventilation are the preoperative clinical condition (such as Osserman's class), ${ }^{18}$ or the intraoperative use of muscle relaxants. ${ }^{2}$ In our series, none of the seven Osserman class III patients suffered from respiratory complications.

In conclusion, the use of a propofol infusion or sevoflurane for maintenance of anesthesia without muscle-relaxants plus an $i v$ sufentanil infusion for intra and postoperative analgesia offered good intra- and postoperative conditions and no or minimal changes in neuromuscular function. Moreover, spontaneous ventilation at the end of the surgical procedure was effectively restored with no residual muscle weakness in both groups and no patient suffered from postoperative respiratory depression that required tracheal intubation. A very early extubation technique is feasible in myasthenic patients either with propofol or sevoflurane general anesthesia without muscle relaxants.

\section{References}

1 Baraka A. Anaesthesia and myasthenia gravis. Can J Anaesth 1992; 39: 476-86.

2 Chevalley C, Spiliopoulos A, de Perrot M, Tschopp JM, Licker $M$. Perioperative medical management and outcome following thymectomy for myasthenia gravis. Can J Anesth 2001; 48: 446-51.

3 Azar I. The response of patients with neuromuscular disorders to muscle relaxants: a review. Anesthesiology 1984; 61: 173-87.

4 Viby-Mogensen J, Engbaek J, Eriksson LI, et al. Good Clinical Research Practice (GCRP) in pharmacodynamic studies of neuromuscular blocking agents. Acta Anaesthesiol Scand 1996; 40: 59-74. 
5 Eisenkraft JB, Papatestas AE, Kahn CH, Mora CT, Fagerstrom R, Genkins G. Predicting the need for postoperative mechanical ventilation in myasthenia gravis. Anesthesiology 1986; 65: 79-82.

6 Baraka $A$. Onset of neuromuscular block in myasthenic patients (Letter). Br J Anesth 1992; 69: 227-8.

7 Roelofse JA, Roth PJ. Total intravenous anesthesia with propofol for thymectomy in a patient with myasthenia gravis. Anesth Prog 1993; 40: 127-9.

8 El-Dawlatly AA, Ashour $M H$. Anaesthesia for thymectomy in myasthenia gravis: a non-muscle-relaxant technique. Anaesth Intensive Care 1994; 22: 458-60.

9 O'Flaherty D, Pennant JH, Rao K, Giesecke AH. Total intravenous anesthesia with propofol for transsternal thymectomy in myasthenia gravis. J Clin Anesth 1992; 4: 241-4.

10 De Grood PMRM, Mitsukuri S, Van Egmond J, Rutten JMJ, Crul JF. Comparison of etomidate and propofol for anaesthesia in microlaryngeal surgery. Anaesthesia 1987; 42: 366-72.

11 Scheller MS, Zornow MH, Saidman LJ. Tracheal intubation without the use of muscle relaxants: a technique using propofol and varying doses of alfentanil. Anesth Analg 1992; 75: 788-93.

12 Nilsson E, Palohelmo M, Muller K, Heinonem J. Halothane-induced variability in the neuromuscular transmission of patients with myasthenia gravis. Acta Anaesthesiol Scand 1989; 33: 395-401.

13 Nilsson E, Muller K. Neuromuscular effects of isoflurane in patients with myasthenia gravis. Acta Anaesthesiol Scand 1990; 34: 126-31.

14 Rowbottom SJ. Isoflurane for thymectomy in myasthenia gravis. Anaesth Intensive Care 1989; 17: 444-7.

15 Sebel PS, Lowdon JD. Propofol: a new intravenous anesthetic. Anesthesiology 1989; 71: 260-77.

16 Inomata $S$, Watanabe S, Taguchi M, Okada M. Endtidal sevoflurane concentration for tracheal intubation and minimal alveolar concentration in pediatric patients. Anesthesiology 1994: 80: 93-6.

17 Chan KH, Yang MW, Huang MH, et al. A comparison between vecuronium and atracurium in myasthenia gravis. Acta Anaesthesiol Scand 1993; 37: 679-82.

18 Naguib M, El Dawlatly AA, Ashour M, Bamgboye EA. Multivariate determinants of the need for postoperative ventilation in myasthenia gravis. Can J Anaesth 1996; 43: 1006-13. 